\title{
Modeling the global biogeochemical cycle of carbon and nitrogen in the system atmosphere- plant-soil
}

\author{
A. I. Kurbatova ${ }^{1, *}, A . M$. Tarko $^{2}$, and P. V. Kozhevnikova ${ }^{1}$ \\ ${ }^{1}$ Peoples' Friendship University of Russia (RUDN University), Faculty of Ecology, \\ 6 Miklukho-Maklaya Street, Moscow, 117198, Russian Federation \\ ${ }^{2}$ Dorodnitsyn Computing Center of the Federal Research Center (Computer Science and Control, \\ Russian Academy of Sciences), Vavilova Street 40, Moscow, 119991 Russian Federation
}

\begin{abstract}
The modeling of the global biogeochemical cycle of carbon and nitrogen against the background of global warming and other anthropogenic impacts on the biosphere is carried out. It is shown that in the process of absorption of anthropogenic $\mathrm{CO} 2$ emissions into the atmosphere during global warming, the nitrogen cycle is significantly intensified and contributes to more efficient absorption of emissions. The greater the dependence of productivity on nitrogen nutrition, the bigger the degree of carbon absorption and, thus, the larger the degree of compensation of the investigated effects. Generally, soil absorbs a significant share of carbon dioxide emissions and therefore holds much significance in absorption. The role of litter is relevant in absorbing emissions. Having 10 times less mass than humus, it absorbs more carbon than humus.
\end{abstract}

\section{Model description}

A mathematical model that takes into account the biogeochemical cycles of carbon and nitrogen in the atmosphere-plants-soil (APS) system is developed. The carbon cycle determines the greenhouse effect of carbon dioxide from anthropogenic $\mathrm{CO}_{2}$ emissions into the atmosphere by burning fossil fuels (coal, oil, gas) growth, and the nitrogen cycle reflects the role of nitrogen nutrition of plants in the biosphere dynamics. The phase variables of the model are carbon dioxide of atmospheric carbon, carbon and nitrogen of terrestrial vegetation, carbon and nitrogen of litter, carbon and nitrogen of humus, and nitrogen of soil in plant-digestible form.

The model parameter is the average global temperature of the atmosphere. The scheme of carbon and nitrogen cycles adopted in the model is shown in Fig. 1. Carbon and nitrogen go from level to level, for example, during photosynthesis carbon from "Atmospheric carbon" passes into "Plant carbon" and "Nitrogen in digestible form" passes into "Plant nitrogen".

\footnotetext{
*Corresponding author: kurbatova_ai@rudn.university
} 


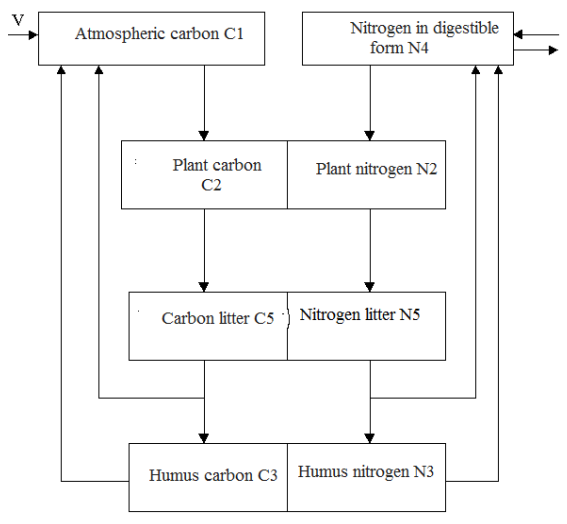

Fig. 1. Scheme of carbon and nitrogen cycle in the model of global system atmosphere-plant-soil.

We take into account that nitrogen of soil in plant-digestible form is spent on the construction of plant biomass, and the remaining part is taken out of the system within one year. Since the residence time of nitrogen in the digestible form is less than 1 year, and its mass is much less than that of plants and humus we are interested in, the amount of nitrogen in the digestible form cannot be calculated.

We can assume with sufficient accuracy that the ratio of carbon to nitrogen in plants remains constant. Then the ratio of annual production expressed in carbon to annual production expressed in nitrogen is constant.

Let us consider the dependencies for fluxes. In the model, photosynthesis and carbon consumption for primary annual production depend on the concentration of $\mathrm{CO}_{2}$ in the atmosphere (greenhouse effect), the amount of nitrogen in the digestible form in the soil and the temperature of the atmosphere. The coefficient $\gamma$ expresses the dependence of annual production on the amount of nitrogen in the digestible form, if the value of $\gamma$ is close to zero, then this dependence is small, if $\gamma=1$, the dependence is maximum. We believe that the intensity of vegetation die-off is proportional to their biomass.

We assume that the decomposition of carbon and nitrogen litter occurs independently at different specific rates, the ratio of carbon fluxes resulting from decomposition of litter into atmosphere and humus is constant, and the ratio of nitrogen fluxes passing from litter to humus and digestible form is constant.

The decomposition of carbon and nitrogen litter at an increase in temperature is considered to obey the law of Van-Goff. We believe that the decomposition of carbon and nitrogen of humus occurs independently, linearly, with different specific velocities, depends on the mass of humus and is obeys the temperature law of Van-Goff.

The unit of time in the model is one year. For the initial state of the model we take the state in the pre-anthropogenic period, for which we assume the state in 1860 . We believe that in the pre-anthropogenic period the carbon fluxes in the system were balanced and the amount of carbon in the ATM system was constant.

The data characterizing the carbon and nitrogen cycles are taken from [1-5]. The initial values of the variables and the coefficients were selected as follows:

atmospheric carbon - $600 \mathrm{Gt} \mathrm{C}$, vegetation carbon - $1000 \mathrm{Gt} \mathrm{C}$, humus carbon - $1200 \mathrm{Gt}$ $\mathrm{C}$, litter carbon $-120 \mathrm{Gt} \mathrm{C}$, annual vegetation production - $60 \mathrm{Gt} \mathrm{C} \mathrm{/} \mathrm{year.} \mathrm{The} \mathrm{ratio} \mathrm{of}$ carbon to nitrogen in the wood of plants is 40 , in humus 10 , in litter 25 . 


\section{Modeling results. The role of nitrogen nutrition of plants and the importance of litter in the dynamics of the biosphere}

The dynamic properties of the model under the influence of industrial emissions in the period 1860-2060 were studied. Let us consider the scenario in which industrial $\mathrm{CO}_{2}$ emissions into the atmosphere took place in 1860-2000, their values were taken from [5, 7]. After 2000, emissions growth was assumed to be $1.44 \%$ per year. Several computer calculations were carried out with different values of the coefficient $\gamma$, expressing the dependence of the annual production on the amount of nitrogen in digestible form. The increase in carbon dioxide due to the greenhouse effect is accompanied by an increase in the temperature of the atmosphere. Both factors lead to an increase in annual production of plants, and an increase in temperature leads to an increase in the rate of decomposition of humus and litter. As a result, a part of $\mathrm{CO} 2$ from the atmosphere is absorbed by plants, litter and humus. Fig. 2 presents the calculations of the increase in the amount of humus in this scenario for the three options for the value of the coefficient. It can be seen that the amount of humus grows approximately exponentially, and, the more $\gamma$ (i.e., the stronger the dependence of annual production on assimilable nitrogen), the faster the humus grows. The growth of humus over the period considered is $1.57-1.87 \%$.

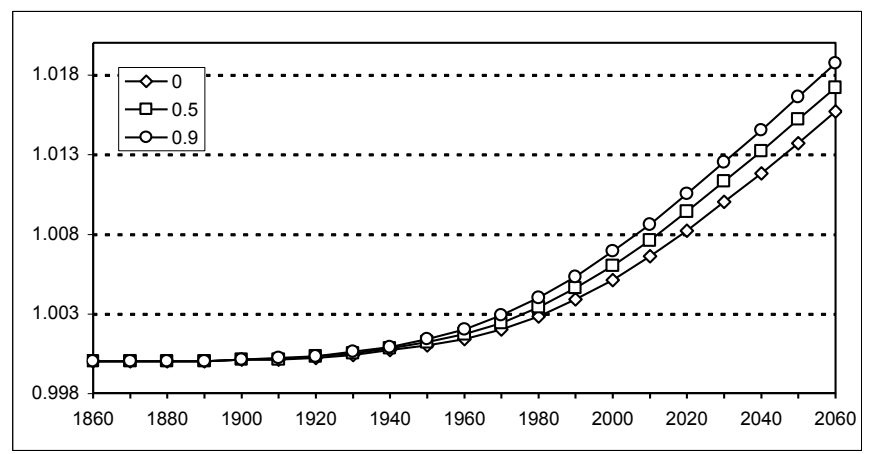

Fig. 2. Dynamics of relative change of humus at $\mathrm{CO}_{2}$ emissions into the atmosphere in 1860-2060 at different values of $\gamma(\gamma=0, \gamma=0.5, \gamma=0.9)$

Calculations of litter growth for the three options for the value of the coefficient $\gamma$ show that, as in the case of humus, the more $\gamma$ the faster the litter grows. The growth of litter for the period considered is $8.9-9.7 \%$. Calculations of the amount of carbon absorbed by plants, litter and humus in 1860-2000 are shown in Table 1. By this year, plants absorb 101.3-115-2 Gt C, 11.9-14.4 Gt C is accumulated in the litter, and 7.2-9.6 Gt C is accumulated in humus. The absorption of atmospheric $\mathrm{CO}_{2}$ emissions by terrestrial ecosystems is significant. It is about half of all emissions. The most $\mathrm{CO}_{2}$ is absorbed by plants, followed by litter and humus. Let us consider the ratio of absorbed quantities of $\mathrm{CO}_{2}$ by different reservoirs of the biosphere. It was found that the ratio of the absorption of emissions does not correspond to the initial mass of the respective tanks. The initial amount of carbon in the vegetation and humus is about the same, and the litter contains about $10 \%$ of their mass. However, plants absorb the largest amount of carbon $-82.8-64.4 \%$ of all absorbed $\mathrm{CO}_{2}$, humus absorbs the smallest amount (6-7\%), and litter is between them (9.7$10.4 \%$ ). Thus, the soil as a whole absorbs a significant share of carbon dioxide emissions, therefore, it has an important global importance in absorption. It is worthwhile noting that there is an important role of litter in absorption of emissions. Having 10 times less mass 
than humus, it absorbs more carbon than humus. Let us consider quantitatively to what extent the consideration of nitrogen nutrition of plants is important in the analysis of anthropogenic activity. According to the calculations, the assimilable nitrogen increases in the period 1860-2060, as well as the withdrawal of nitrogen into plants, whereas its output from the APR system decreases. This means that in the process of $\mathrm{CO}_{2}$ emissions absorption the nitrogen cycle is intensified and the degree of its openness decreases, which thus contributes to a stronger absorption of atmospheric carbon dioxide. The calculations show that the greater the dependence of productivity on nitrogen nutrition, the greater the degree of carbon absorption and, thus, the greater the degree of compensation of the investigated effects. Two options can be considered. The first one does not take into account nitrogen nutrition $(\gamma=0)$, the second one implies that nitrogen nutrition affects productivity to the maximum $(\gamma=0.9)$. In these cases, the increase in the mass of vegetation, litter and humus will differ by $11.7 \%$ and $20.8 \%$ and $34 \%$, respectively. The increase in atmospheric $\mathrm{CO}_{2}$ concentration, for example, by the year 2000 will be $25.5 \%$ and $22.7 \%$, respectively. There is no big difference in the last two numbers, therefore, while the importance of nitrogen nutrition is of great value, the role of the nitrogen cycle in the calculation of the effects of carbon dioxide emissions is not required.

Table 1. Absorption of carbon dioxide emissions in terrestrial ecosystems in $1860-2000$ (Mt c).

\begin{tabular}{|c|c|c|c|}
\hline G & Plants & Litter & Humus \\
\hline 0 & 103.1 & 11.9 & 7.2 \\
\hline 0.5 & 109.4 & 13.2 & 8.4 \\
\hline 0.9 & 115.2 & 14.4 & 9.6 \\
\hline
\end{tabular}

The research was supported financially by Russian Foundation for Basic Research (Project No. 17-01-00693a). The publication has been prepared with the support of the "RUDN University" Program 5-100.

\section{References}

1. A. I. Kurbatova, A. M. Tarko, Vestn. Univ. Druzhby Nar. im. Patrisa Lumumby, Ser. Ekol. Bezop. Zhiznedeyat. 2, 7-25 (2015)

2. G. Marland, T. Boden, B. Andres, Global, Regional and National Fossil-Fuel $\mathrm{CO}_{2}$ Emissions (Oak Ridge: Carbon Dioxide Inf. Anal. Cent., Oak Ridge Natl. Lab., 2010)

3. J. S. Olson, J. A. Watts, L. J. Allison, Major World Ecosystem Complexes Ranked by Carbon in Live Vegetation:A Database (Oak Ridge: Carbon Dioxide Inf. Anal.Cent., Oak Ridge Natl. Lab., 2001)

4. G. E. Likens, F. H. Borman, N. M. Johnson, Interaction between major biogeochemical cycles in terrestrial ecosystems (Some Perspectives of the Major Biogeochemical Cycles. SCOPE 17 - N.Y., Willley, 93-112, 1981)

5. G. Marland, T. Boden, B. Andres, Global $\mathrm{CO}_{2}$ Global $\mathrm{CO}_{2}$ Emissions from Fossil-Fuel Burning, Cement Manufacture, and Gas Flaring: 1751-2008. NDP-030 (Carbon Dioxide Information Analysis Center. Oak Ridge National Laboratory, Oak Ridge, Tennessee, 2011)

6. SCOPE 17 - N.Y., Willey (1981)

7. W. H. Schlesinger, Ann. Rev. Ecol. Syst. 8, 51-81 (1974) 